Atos de Pesquisa em Educação - ISSN 1809-0354

Blumenau, v. 13, n.2, p.271-295, mai./ago. 2018

DOI: http://dx.doi.org/10.7867/1809-0354.2018v13n2p271-295

\title{
RELAÇÕES SOCIOAMBIENTAIS: REFLEXÕES SOBRE INTERCULTURA E CURRÍCULO
}

\author{
SOCIAL ENVIRONMENTAL RELATIONS: REFLECTING ON AN \\ INTERCULTURAL CURRICULUM
}

\author{
FARACO, Cristina Machado Oliveira \\ UNISUL- Universidade do Sul de Santa Catarina \\ cristina_faraco@yahoo.com.br \\ VALENÇA, Vera Lúcia Chacon \\ UNISUL- Universidade do Sul de Santa Catarina \\ veravalenca@uol.com.br
}

\begin{abstract}
RESUMO
Este artigo busca refletir sobre o currículo na perspectiva intercultural, tendo em vista superar a abordagem tradicional ainda vigente nas escolas. Partindo da experiência que a pesquisadora vem desenvolvendo como professora da rede estadual de Santa Catarina, apresenta-se como metodologia um estudo histórico e empírico de Garopaba no contexto das relações entre diferentes culturas que, interagindo com os ambientes locais, construíram e ainda constroem a identidade do município. Os resultados levam a inferir sobre a necessidade de revisão do currículo padronizado e universalizado nas escolas, no sentido de educar para conhecimentos científicos acadêmicos de relevância global, mas que também contemple os saberes da comunidade, a complexidade e as particularidades sociais e ambientais da região.
\end{abstract}

PALAVRAS-CHAVE: Currículo. Educação. Intercultura. Relações Socioambientais.

\section{ABSTRACT}

This article examines a specific curriculum from an intercultural perspective, with a view of overcoming the traditional teaching approach still prevalent in various Brazilian schools. Using classroom experience acquired in the state of Santa Catarina contributing as methodology, this is an historical and empirical study of Garopaba, Brazil in the context of relations between differing cultures as they interact with local environments - significant issues that built and continue to build a municipal identity. The results of this study lead one to perceive a need to reassess the standard school curriculum in an effort to provide a basis of globally relevant scientific knowledge while also considering the popular wisdom and unique characteristics of the community and the social and environmental complexities of the region.

KEY WORDS: Curriculum. Education. Intercultural. Social Environmental Relations.

\section{INTRODUÇÃO}




\section{Atos de Pesquisa em Educação - ISSN 1809-0354 \\ Blumenau, v. 13, n.2, p.271-295, mai./ago. 2018 \\ DOI: http://dx.doi.org/10.7867/1809-0354.2018v13n2p271-295}

A educação no Brasil, mesmo após estudos históricos e críticos, ainda reproduz, essencialmente, uma pedagogia tradicional baseada na transmissão de conteúdos prontos e sem o protagonismo dos alunos. O estudo do meio ambiente é realizado de modo limitado, restringindo-se ao âmbito das características físicas e biológicas desconectadas do ambiente humano e cultural. A Natureza aparece nos livros didáticos de forma simplista, em geral, restrita às perspectivas como recurso natural ou como ambiente contemplativo a ser preservado, quase intocado. Em ambos os casos, o humano é desarticulado do ambiente, dos espaços em que vive, como se a Natureza estivesse ao alcance das pessoas, mas as pessoas não estivessem ao alcance da Natureza. Os desdobramentos deste processo educativo favoreceram o contexto histórico e socioambiental em que se vive hoje, em que as necessidades e vontades humanas sobrepõem-se aos ciclos naturais, produzindo consequências de degradação da vida; e também, de que há uma forma cultural dominante, universal, que se sobrepõe a todas as outras culturas. Como se os humanos existissem numa outra esfera fora do meio ambiente, onde o ser social e cultural é desconectado do ser natural e ecológico.

Esta visão desarticulada do mundo trouxe efeitos nocivos em diversos aspectos no que se refere não só às políticas sociais, ambientais e econômicas, como também às relações socioambientais. Ao ver o mundo cultural desconectado do meio ambiente e as pessoas segregadas entre $\mathrm{si}$, a sociedade tende a explorar os bens ambientais sem considerar as consequências de seu ato transformador e destruidor sobre o mundo e sobre si mesmo. Não se coloca como responsável pelas consequências das escolhas que faz. Num mundo cultural desconectado do meio ambiente, habitado por pessoas segregadas entre si, que não assumem responsabilidade sobre seus atos, podem ocorrer impactos e consequências irreparáveis.

Por isso, o currículo adotado pela escola em suas políticas educacionais é de suma importância para concretizar, na prática, uma educação voltada à sociedade que se quer formar. De modo a determinar e a sistematizar o conhecimento, a educação brasileira segue uma legislação curricular específica, as Diretrizes Curriculares Nacionais para a Educação Básica (BRASIL, 2013). De acordo com Silva (2010), o sentido moderno do currículo está ligado à organização e ao método de ensino. Mas, na concepção de Saviani (1999), é um currículo que tradicionalmente se 
organiza num sentido de promover o controle ideológico pelo Estado, de modo a instruir as pessoas conforme os objetivos e interesses do regime vigente, e depois avaliá-las, para garantir que suas ideias e práticas sejam assimiladas. O currículo, nesta perspectiva, é linear, sequencial, estático, disciplinar e fragmentado, desconsiderando a estrutura histórica e cultural, e as múltiplas inter-relações dos diferentes aspectos no todo.

Neste contexto, o presente artigo objetiva contribuir para as discussões no campo da educação na perspectiva intercultural, em superação à abordagem tradicional ainda vigente. Partindo da experiência que a pesquisadora vem desenvolvendo como professora de Biologia e Ciências na Escola de Educação Básica Professor José Rodrigues Lopes, apresenta-se como metodologia um estudo histórico e empírico de Garopaba no contexto das relações entre diferentes culturas que, interagindo com os ambientes locais, construíram e ainda constroem a identidade do município.

Sem a intenção de esgotar as discussões sobre o tema neste artigo, o estudo sugere a revisão do currículo padrão universalizado, no sentido de possibilitar que as escolas construam seus próprios currículos de forma a educar para os conhecimentos científicos de relevância global, contemplando a complexidade e as particularidades sociais e ambientais de cada região.

\section{INTERCULTURA E CURRÍCULO}

Existem inúmeros conceitos de cultura, entre os quais serão abordados neste artigo aqueles utilizados por Zigmunt Bauman, Fritjof Capra e Edgar Morin.

No entender de Bauman (2012), existem três formas conceituais para descrevê-la: primeira, como conceito hierárquico, na medida em que diferencia as pessoas quanto ao domínio ou não dos valores e competências do modelo cultural hegemônico. Segunda, como conceito diferencial, no sentido de ser um sistema de características que distingue uma comunidade de outra, constituindo uma entidade singular, que é feita pelo homem e que faz o homem, numa relação histórica e dialética. $E$ terceira, como conceito genérico, que é construído na visão dicotômica de 


\section{Atos de Pesquisa em Educação - ISSN 1809-0354 \\ Blumenau, v. 13, n.2, p.271-295, mai./ago. 2018 \\ DOI: http://dx.doi.org/10.7867/1809-0354.2018v13n2p271-295}

mundo humano-mundo natural, que une a espécie humana distinguindo-a de tudo o mais, como um denominador comum da humanidade.

Para Capra (2003), a cultura é criada e sustentada por uma rede de processos que geram significados que são transmitidos de geração a geração e se reproduzem em cada indivíduo. Não há sociedade humana sem cultura e cada manifestação cultural é singular. Mas a singularidade não pode ser vista de forma fechada. A riqueza da diversidade está no intercâmbio das diferentes culturas que propagam e assimilam diferentes aspectos entre si. Por outro lado, a dominação de uma cultura sobre as outras tem efeito destruidor ao impor seus valores, ideais e fazeres de modo opressor e agressivo (como a cultura colonizadora europeia sobre as indígenas) ou de modo mais sutil e pragmático (como a cultura de produção econômica industrial sobre as culturas de produção econômica familiar, por exemplo).

A cultura, no pensamento de Morin (2003), tem papel no controle da existência da sociedade e na conservação da complexidade psicológica e social. É constituída pelo conjunto dos saberes, fazeres, regras, estratégias, ideias, valores e mitos. O ser humano e, consequentemente, a cultura, tem natureza singular e múltipla. O indivíduo apresenta características particulares em sua realidade e imaginário, e, ao mesmo tempo, partilha suas propriedades biológicas e psicológicas com as outras pessoas do seu círculo social, que, por sua vez, interagem de forma complexa com seus similares e as outras sociedades construindo a humanidade. Por isso, Morin (2003) fala da cultura humana existente por meio das culturas, que a cultura da humanidade faz-se pela diversidade e pela multiplicidade cultural.

Partilhando destes olhares, concorda-se com Bauman (2012) quando afirma que cultura não é um sistema petrificado que escolhe o que é normal e exclui o que é desviante, mas, sim, a presença de uma matriz de permutações possíveis e inconclusas em constante mudança. Nesta perspectiva de multiplicidade e transformação, cogita-se a possibilidade de se fazer não só um currículo voltado para a educação em conhecimentos acadêmicos científicos, como também para os saberes, as necessidades e interesses peculiares das diferentes culturas e manifestas nas diferentes regiões. Não uma soma de perspectivas, mas como uma articulação entre as duas perspectivas, em que os diferentes saberes das diferentes culturas dialoguem e tragam o melhor daquilo que são. Um currículo que não seja importado, 
nem rígido, que não venha pronto 'de cima', mas que seja construído pelos sujeitos da comunidade escolar, dentro da sua realidade, considerando a superação dos seus problemas e conflitos nos processos de ensino e aprendizagem.

Para entender a abordagem intercultural, é preciso compreender o panorama da temática no Brasil e no mundo. Num primeiro momento, o discurso referia-se à questão multicultural que teve a influência de movimentos europeus na segunda metade do século XX. O conceito de multiculturalidade é reconhecido com relevância e amplamente discutido nos meios educacionais brasileiros, sendo a pluralidade cultural abordada como tema transversal pelos Parâmetros Curriculares Nacionais (BRASIL, 1997), documento que norteou a determinação das Diretrizes Curriculares Nacionais (BRASIL, 2013). Em alternativa à perspectiva etnocêntrica, estas discussões trazem a proposta de convivência democrática entre as diferentes culturas e grupos sociais, baseada no respeito às diferenças e reconhecimento na paridade de direitos (FLEURI, 2003), e visam promover a relação e o respeito entre grupos socioculturais por meio de processos democráticos e do diálogo.

Em contrapartida, falar em universalização da cultura é referir-se a um modelo que discipline a sociedade a seguir um ideal particular dominante em detrimento das demais formas culturais. Para McLaren (2001), universalismo é um particularismo mascarado. Dado o histórico do mundo ocidental, universalizar a cultura é equivalente a impor à força física, política e econômica, a cultura de produção e consumo capitalistas, com base na opressão e exploração tanto do homem pelo homem quanto da Natureza pelo homem. Enquanto o capitalismo desenfreado ainda for o modo econômico dominante na sociedade, mesmo o multiculturalismo será subordinado aos seus ideais, aumentando tanto a segregação quanto o fetichismo em grupos como de gênero, etnia, classe, idade e religião.

Por mais que exista uma grande quantidade de características universais de sistemas culturais e sociais, para Bauman (2012, p. 75): "usar o termo cultura como o artigo indefinido só faz sentido se sustentado pelo pressuposto implícito de que nada que seja universal pode ser um fenômeno cultural". A presença de características universais não se refere à cultura em si, mas aos seres humanos. Ainda, afirma o autor, "[...] os chamados universais são apenas similaridades desnudadas pelo processo de comparar diferentes entidades culturais" (BAUMAN, 2012, p. 77). Ser 


\section{Atos de Pesquisa em Educação - ISSN 1809-0354 \\ Blumenau, v. 13, n.2, p.271-295, mai./ago. 2018 \\ DOI: http://dx.doi.org/10.7867/1809-0354.2018v13n2p271-295}

semelhante não é ser igual e, apesar de apresentar alguns aspectos semelhantes, culturas diferentes ainda apresentam suas singularidades.

Como meio de superar o reducionismo da abordagem universal de cultura, Fleuri (2003) aborda uma nova perspectiva epistemológica de compreensão das identidades e relações interculturais. A intercultura abre campo para o debate entre as variadas concepções e propostas referentes aos problemas que envolvem as relações entre os diferentes processos socioculturais e de identidade. Objeto de estudo interdisciplinar e transversal, a intercultura teoriza a complexidade, numa reflexão para além da pluralidade e da diversidade dos discursos em vigor. $O$ foco passa a ser a complexidade cultural de identidade e relações sociais do sujeito, considerando o respeito à alteridade e às suas particularidades dentro do todo social em que ele vive e interage. Alinhados a esta concepção, Coppete, Fleuri e Stoltz (2012) defendem a ideia de que a educação intercultural favorece a construção de um projeto comum à sociedade, em que é possível integrar as diferenças dialeticamente. Tal educação foca a construção de uma sociedade democrática e plural capaz de articular políticas de igualdade com políticas de identidade.

Ainda hoje, há discussões a respeito da multiplicidade de termos que se referem à mesma ideia, como multicultura e intercultura. Para Fleuri (2009 apud Coppete, Fleuri e Stoltz, 2012), é possível identificar três aspectos que delimitam e diferenciam o multiculturalismo: o reconhecimento ou não das hierarquias de poder nas relações entre os diferentes grupos culturais; a visão mais essencializada ou dinâmica da identidade cultural de certos grupos; e a articulação ou não entre as desigualdades socioeconômicas e as diferenças culturais. Independentemente de uma ou outra posição, os problemas relacionados às diferenças e às identidades culturais são importantes para a educação, em especial, no que se referem às práticas pedagógicas no âmbito escolar. Neste contexto, para o autor, a educação que envolve a multicultura e suas inter-relações pode ser abordada sob duas perspectivas: enquanto movimento a favor da equidade social e como uma abordagem curricular alternativa à abordagem monocultural ainda vigente nas escolas. Mas, é importante ter um olhar crítico sobre a coerência entre a fala e a realidade. Na visão de Walsh (2009), o multiculturalismo é um discurso que foi apropriado pelo (neo)liberalismo atual no intuito de fazer pensar que o reconhecimento à diversidade e sua inclusão no 
discurso resolverão os problemas do colonialismo. Sua essência está na integração das diferenças considerando suas particularidades nas tomadas de decisões, não servindo apenas de meio politicamente correto para a solução de conflitos étnicos.

No campo educativo, o termo intercultura, que passou a ser utilizado na década de 80 pelo Conselho Europeu, surgiu da necessidade de tratar a questão da entrada de estrangeiros nas escolas:

No plano educacional, a interculturalidade sinaliza um projeto cujo objetivo é a intervenção nas mudanças induzidas a partir do contato e da interação entre sujeitos e sua diversidade, de maneira que promova atitudes abertas ao confronto e conduza processos integradores entre culturas (COPPETE; FLEURI; STOLTZ, 2012, p. 239).

Para os autores supracitados, a educação intercultural diferencia-se por enfatizar a relação entre os sujeitos culturais diferentes, enquanto a educação multicultural busca o reconhecimento identitário das minorias étnicas. A multiculturalidade, neste ponto de vista, é compreendida como um indicador da realidade de coexistência de grupos culturais distintos numa mesma sociedade. Já a interculturalidade, é um indicador do conjunto de propostas de convivência e de relação democrática e criativa entre as diferentes culturas. Algo que vai além das estruturas de dominação sociocultural e de destruição sistemática da Natureza.

[...] a intercultura se torna um objeto de estudo transversal, interdisciplinar e complexo às temáticas de cultura, de etnia, de gerações, de gênero, de movimento e de ação social. [...] É um processo permanente e inacabado, fortemente marcado pela intenção de promover relações democráticas e dialógicas entre grupos e culturas diversas (COPPETE; FLEURI; STOLTZ, 2012, p. 241).

Conforme estes autores, a educação numa perspectiva intercultural propõe mudanças na forma de pensar e na forma de sentir que levem à compreensão do que os outros pensam e sentem:

No que implica uma educação de abordagem intercultural? O objetivo maior
dessa abordagem consiste em auxiliar as pessoas a se apropriarem do
código que possibilita acessar o universo do outro, ou seja, os valores, a
história, a maneira de pensar, de viver, entre outros. [...] Assim, é possível
inferir que a educação intercultural sugere que as pessoas aprendam e se
habituem a olhar, mediados por uma ótica diferente. Propõe mudanças
cognitivas e emocionais que as levem a compreender como os outros
pensam e sentem; e nesse processo retornem a si mesmos mais conscientes
de suas próprias raízes culturais (COPPETE; FLEURI; STOLTZ, 2012, p.
244). A abordagem da educação intercultural, de acordo com estes autores, é emancipatória e constituída na inter-relação entre as diferentes culturas, na e pela percepção da multiplicidade de olhares demandando um encontro entre elas, em que as diferenças sejam tensões produtivas que podem ser ponto de partida para práticas 
escolares, educativas e construção de conhecimento relevantes para os diferentes grupos sociais envolvidos. Ao mesmo tempo em que se ressignificam, preservando suas singularidades e diversidades, também estabelecem relações e vínculos com outras culturas, possibilitando sua convivência.

No contexto educacional, a abordagem intercultural tem sua importância por buscar estabelecer novos relacionamentos que possam ir além dos limites culturais locais, oportunizando sua expressão e o acesso a outras realidades, favorecendo uma escola aberta à diversidade. Uma escola que busca a integração entre as diversas culturas. Que considere a diversidade de culturas que se expressam por meio das artes, da literatura, da linguagem, dos costumes, das relações que se estabelecem tanto dentro da sociedade quanto desta com o seu espaço e tempo. Como Bauman (2012) afirma, o conceito de cultura é um dos termos que representam a práxis humana. Práxis como ação reflexiva da sociedade sobre o ambiente. E o ambiente é resultado deste movimento dialético entre as relações e formas culturais com as manifestações físicas, químicas e biológicas não humanas, compondo uma estrutura ambiental complexa e metamórfica. $O$ todo não se constitui apenas pela soma de suas partes, neste caso, pela soma do ambiente cultural ao ambiente natural. Entretanto, faz-se como resultado das interações sinérgicas entre eles, com eles, sendo composto por eles, transformando e transformado por eles, e sendo eles. A sociedade e a cultura não são aspectos separados do ambiente, mas o constituem e são constituídos de forma inter-relacionada e dialética.

Essa concepção da totalidade do ambiente tem raízes remotas. As culturas originais brasileiras (indígenas), por exemplo, veem-se unas com a Natureza. Entendem, com base em Jecupé (1998), que tudo se desdobra de uma fonte única, formando uma trama sagrada de inter-relações onde tudo se conecta a tudo. Para os povos da floresta, os homens são parte da Terra e a Terra é parte dos homens. Não há separação de exclusão, pois a relação é de unicidade. De acordo com Gonçalves (1989), o homem, por natureza, produz cultura, e a Natureza e a cultura condicionam uma à outra, reciprocamente. A forma como cada cultura vê e interage com a Natureza é um elemento-chave para compreender as relações socioambientais que a caracterizam. 


\section{AS RELAÇÕES SOCIOAMBIENTAIS NO CONTEXTO DA INTERCULTURA DE GAROPABA}

Existe uma cultura hegemônica ou os espaços são construídos pelas interrelações entre as diferentes culturas? Como se dá a relação entre as culturas e o meio ambiente? Na busca de alguns elementos que elucidem estas questões, apresentase uma reflexão sobre a cidade de Garopaba, em Santa Catarina, mostrando a importância da intercultura na construção social e da sinergia das inter-relações entre os diferentes grupos culturais humanos e os ecossistemas no qual e com o qual interagem. Esta discussão baseia-se em dados empíricos obtidos em investigação de campo por meio de pesquisas e práticas eco pedagógicas realizadas nos últimos 12 anos nesta localidade como professora de Biologia e Ciências da rede estadual de ensino na Escola de Educação Básica Professor José Rodrigues Lopes. Também se baseia em pesquisa bibliográfica das obras de Valentim (2007), professor e antigo morador do município, Besen (1996), professor de História das Religiões que escreveu recordações da Freguesia de Garopaba, e materiais de pesquisadores do Grupo de Pesquisa em Educação Patrimonial e Arqueologia da UNISUL (GRUPEP) e dados do IBGE (S.d).

Os resultados do estudo mostram que Garopaba abrange, além de uma acentuada diversidade de ecossistemas - como suas nove praias, vestígios florestais atlânticos, dunas, mangues e restingas - também uma diversidade de culturas que coexistem em relações tanto cooperativas quanto de conflito, nesta paisagem. Relações que construíram as identidades culturais locais que hoje se caracterizam economicamente, entre outras atividades, pelo extrativismo marinho por meio da pesca artesanal, pela agricultura familiar e de engenho na costa atlântica, pela produção fabril de produtos esportivos e pelo comércio sazonal de verão. Segundo dados do IBGE (S.d), o Índice de Desenvolvimento Humano (IDH), em 2010, foi de 0,753 , o que indica um aumento na qualidade de vida em relação ao censo de 2000 , quando o índice foi de 0,635 . Isto mostra uma melhoria substancial neste período de 10 anos, fato que tem atraído cada vez mais pessoas de diferentes estados e países que migram para a região em busca de descanso, aventura e melhores oportunidades de vida. 
A ocupação humana na região é muito antiga. Vestígios arqueológicos do sambaqui na península da praia da Barra mostram que Povos Caçadores Coletores viveram em Garopaba há milhares de anos. Conforme estudos realizados por DeBlasis et al. (2007), o estabelecimento destes povos no litoral sul de Santa Catarina ocorreu no período entre 6000 e 1500 anos a.p. Para Farias, Demathé e Silva (2014), marcas circulares e linhas paralelas em baixo relevo, que caracterizam as oficinas líticas de polimento de ferramentas deste mesmo período, também são encontradas nas pedras de diabásio ao longo das praias e dos costões rochosos, além de desenhos rupestres na Pedra do Galeão, no costão da praia do Silveira. Após o desaparecimento destes povos, os ceramistas Tupis-Guaranis, que já praticavam a agricultura - mas ainda exerciam atividades extrativistas - ocuparam o território há cerca de 700 anos a. p. (FARIAS et al. 2011), como indicam artefatos encontrados em sítios arqueológicos localizados nos bairros Gamboa e Encantada.

Quando os portugueses aportaram na baía de Garopaba, em 24 de junho de $1525^{1}$ (25 anos depois da primeira chegada de Pedro Álvares Cabral ao Brasil), começaram as relações entre os europeus e os Guaranis que habitavam a região. Os imigrantes utilizavam a pequena baía como porto seguro para as embarcações e, provavelmente, faziam escambo entre seus produtos e os alimentos, lenha e artesanatos indígenas. Conforme Valentim (2007), europeus e Guaranis tiveram filhos híbridos que se uniram aos índios formando um grupo étnico-cultural denominado Carijó, que apresentava características com influências das duas nações.

Os estudos de Besen (1996) indicam que, em 1666, os imigrantes açorianos formaram o primeiro povoado na margem da enseada chamada, já naquela época pela língua Tupi, de Ygarampaba (em que ' $Y$ refere-se à água, 'garatá' era um tipo de madeira usada para fazer canoas e 'mpaba' representando a enseada), significando 'enseada de barcos', por ser um local seguro e propício para o ancoradouro das embarcações. Contudo, no século XVIII, a imigração açoriana intensificou-se, sem uma organização muito rígida, com a vinda de um grande número de casais. A partir da colonização, houve grande influência recíproca entre as culturas açoriana e indígena, criando uma cultura local bastante rica e sincrética. Os indígenas ensinaram a agricultura da mandioca, da batata, do taiá, do milho e do amendoim, além da

\footnotetext{
${ }^{1}$ Segundo documentos da Prefeitura Municipal de Garopaba (2004).
} 


\section{Atos de Pesquisa em Educação - ISSN 1809-0354 \\ Blumenau, v. 13, n.2, p.271-295, mai./ago. 2018 \\ DOI: http://dx.doi.org/10.7867/1809-0354.2018v13n2p271-295}

preparação do biju e da canjica, e a manufatura de cestarias, redes e esteiras para dormir, enquanto os açorianos trouxeram a laranja, a uva, o café, a banana e a cana, além do gado, dos cavalos, cabras e porcos, introduzindo a pecuária na região. No entanto, para Valentim (2007), os carijós catarinenses, inferiorizados pelos europeus e longe do controle da capital, foram perseguidos e escravizados pelos mamelucos bandeirantes das províncias de São Vicente (atual São Paulo) para trabalharem nas lavouras. Mas, esse povo livre e guerreiro preferia a morte à escravidão, o que determinou o massacre de milhares deles que também morreram em consequência de doenças para as quais não tinham imunidade. Os poucos sobreviventes na região foram catequizados pelos jesuítas e, aos poucos, iam sendo agregados à sociedade de predominância cultural portuguesa, na qual passaram a ser excluídos política, econômica e socialmente, o que não os impediu de contribuir para o patrimônio genético e cultural que constitui a identidade catarinense até hoje.

Em 1795, de acordo com Valentim (2007), foi fundada a armação baleeira de Garopaba, iniciando a caça de cetáceos que foi uma das principais atividades econômicas da época. A caça à baleia era considerada de extrema importância naquele momento, pois fornecia óleo para a iluminação pública, para fazer argamassa para as fortalezas e construções, e barbatanas para a confecção de espartilhos para as mulheres da alta classe. Com a exploração crescente do petróleo e a produção de querosene, a indústria baleeira encontrou o seu fim, até que, em 1967, a última baleia foi abatida em Garopaba, encerrando definitivamente as atividades neste setor. Atualmente, a Baleia Franca é considerada patrimônio natural e é protegida por lei, sendo reconhecida uma Área de Proteção Ambiental (APA) pelo Decreto Federal, de 14 de setembro de 2000 (BRASIL, 2010). A APA da Baleia Franca abrange 156.100ha e cerca de $130 \mathrm{~km}$ de costa, lagoas, mangues e promontórios rochosos entre o sul de Florianópolis (Pântano do Sul) e o Balneário Rincão, ao sul do Cabo de Santa Marta, em Laguna. A exploração turística e de pesquisa do cetáceo desenvolveu-se, a partir de então, por meio de avistamentos por mar, pelo ar e por terra, exercidos por Organizações Não Governamentais (ONG) e empresas turísticas. Mas, por motivo de irregularidades na gestão dos passeios, as atividades embarcadas foram suspensas a partir de 2012, estando sujeitas à análise de impacto ambiental exigida pelo Ministério Público. 
Pessoas originárias de diferentes povos do continente africano foram trazidas em navios também no século XVIII, para o trabalho escravo nas armações, nas fazendas de engenho, na construção de casas e pontes. Com o passar do tempo, integraram-se à comunidade como pescadores e agricultores, após a abolição e, em especial, a partir da década de 1950, quando os eventos sociais como bailes e festejos religiosos deixaram de ser segregados. Para Valentim (2007), após a alforria, muitos senhores passaram a ser patrões, empregando os ex-escravos, doando terras e ajudando a construírem suas casas. Por outro lado, na concepção de Farias et al. (2011), muitos afrodescendentes enfrentaram dificuldades, pois alguns senhores ainda queriam que trabalhassem de graça e passaram a trocar seu trabalho por banana, farinha, café e açúcar para sobreviverem. Com isso, muitos libertos afastaram-se da vila e criaram suas próprias comunidades. Atualmente, existem duas comunidades quilombolas no município de Garopaba: do Morro do Fortunato, no bairro Macacu, ao norte do município, e da Aldeia, no bairro Campo D'uma, ao sul. Com sua participação ativa na sociedade, os descendentes dos africanos trouxeram aspectos religiosos e culturais que enriqueceram a cultura de Garopaba. Estão vivas na cultura local a capoeira, considerada uma arte marcial brasileira, o berimbau e os instrumentos de percussão, e a umbanda, no aspecto espiritual. Existem projetos que se empenham na valorização da cultura e economia das comunidades quilombolas. No Morro do Fortunato, por exemplo, há produção de agricultura familiar orgânica e também doces artesanais que são comercializados.

Mesmo sendo uma região de paisagens bucólicas, um breve episódio na história de Garopaba colocou a cidade no mapa da Guerra dos Farrapos. Com a proclamação da República Juliana, em 1839, em desdobramento da revolução Farroupilha, houve um plano de ataque em Garopaba, para abrir caminho às tropas rebeldes que rumavam para o norte, em direção à Desterro (atual Florianópolis). Estudos de Besen (1996) indicam que soldados, sob o comando de Garibaldi, vieram pelo mar ao sul e acamparam na Encantada, onde foram surpreendidos pelas forças do Governo que vieram do norte, junto à serra - a geografia e a constituição dos ambientes sendo determinantes neste episódio. Os soldados do exército entraram a pé sob a chuva por uma picada a partir da Gamboa, instalando-se na Encantada. Lá, o $2^{\circ}$ Batalhão das tropas imperiais destruiu qualquer resistência em Garopaba e, com 
a perda da batalha, os combatentes republicanos recuaram para Imbituba e depois para Laguna, onde a República Juliana encontrou seu fim, em 15 de novembro do mesmo ano.

Vinte e cinco anos depois, em 1864 - conforme Besen (1996) - o padre italiano Rafael Faraco tornou-se pároco na cidade, onde atuou como forte figura política. Foi quatro vezes deputado estadual, cultivou uva, produziu vinho, reformou a igreja matriz e uniu-se a uma companheira com quem teve oito filhos, que legaram ampla descendência entre as famílias de pescadores locais, contribuindo com novos aspectos culturais e genéticos europeus na construção da sociedade intercultural de Garopaba.

Por muitos anos, consoante relatos das famílias antigas, como os Aguiar e os Faraco, entre períodos de fartura e escassez, predominou o escambo entre os pescadores da praia e os agropecuaristas do engenho, que trocavam estivas, chapéus e esteiras trançadas em palha de butiazeiro, banha de porco, milho, feijão, café, leite, ovos, queijo, cachaça e farinha de mandioca pelos produtos marinhos, como a tainha, a anchova, a garoupa, a viola, a abrótea, a corvina, a manjuva, como também lula, camarão, marisco e lagostas. O peixe que sobrava, como não havia refrigeração elétrica domiciliar, era 'escalado' (salgado e seco ao sol) para ser armazenado ou trocado por serviços.

A partir da década de 1970, de acordo com Valentim (2007), universitários gaúchos e paulistas começaram a acampar com maior frequência nas praias durante o verão e iniciaram a tradição turística da cidade. Hoje, o município recebe turistas e novos moradores provenientes de vários estados do Brasil, inclusive internacionais, como uruguaios, argentinos, norte-americanos e alemães, entre outras nacionalidades. Segundo dados do IBGE (S.d), no último censo realizado em 2010, a população de Garopaba foi registrada em 18.144 habitantes. Em 2014, a quantidade populacional foi estimada em 20.545, valor que sobe drasticamente para cerca de 140.000 nos meses de verão, quando o turismo é mais acentuado. Num fluxo migratório intenso, essas pessoas influenciam e são influenciadas pela cultura de Garopaba.

Atualmente, as relações culturais e socioambientais de Garopaba são permeadas de ações cooperativas e ecológicas, mas também de conflitos e 
degradação. Quanto aos conflitos, há evidente expansão urbana, com problemas relacionados à ocupação de terras em áreas de preservação, como entorno de mananciais, áreas de declive superior a $45^{\circ}$, soterramento e desmatamento de nascentes e lagoas, como a Lagoa das Capivaras. O turismo sem um planejamento rigoroso leva a problemas como a escassez de água e quedas de energia nos meses de verão, quando o fluxo de turistas é mais intenso. Além disso, há acúmulo de lixo neste mesmo período, uma vez que o serviço de recolhimento dos resíduos urbanos não comporta a quantidade produzida na alta temporada. Há conflitos, também, entre pescadores e surfistas, assim como dos pescadores entre si, em especial, na época da safra da tainha, de maio a julho. Ainda, há a exploração do mar pelos navios pesqueiros industriais, que invadem a área de trabalho dos pescadores artesanais, exaurindo as reservas de pesca e trazendo poluição para as águas devido ao despejo de óleo, dejetos e lixo, pelas embarcações.

No entanto, em meio a estes conflitos, também existem relações interculturais cooperativas, nas quais diferentes pessoas de diversas culturas unem-se para buscar soluções para os problemas da comunidade assim como para celebrações. Como exemplos de ações cooperativas, podem-se citar os mutirões de limpeza da Lagoa das Capivaras, promovidos pela Associação Comunitária Amigos do Meio Ambiente (AMA) e de limpeza das praias, como as organizadas pela Associação de Surfistas da Praia da Ferrugem e pelo Rosamor, na Praia do Rosa. Existem diversos grupos que contribuem com ações em diferentes áreas, como o Vida Mar, que promoveu trilhas ecológicas e plantio de mudas nativas na região; o clube de mães e idosos, que reúne pessoas para o convívio por meio de oficinas artesanais e eventos de convivência; a liga feminina de combate ao câncer, que trabalha na prevenção e diagnóstico precoce da doença; a pastoral da saúde, que produz medicamentos fitoterápicos; colônia de pescadores Z12, que organiza e coordena a pesca artesanal local; grupo escoteiro Ilha Terceira, clube dos Desbravadores Gaivotas do Sul, e pessoas voluntárias da sociedade civil que se reúnem para desenvolver ações ligadas à melhoria da qualidade de diferentes aspectos da vida. São grupos que se consolidaram - em meio às limitações estruturais e financeiras - ao longo das últimas décadas, a partir dos esforços de pessoas que acreditam no poder da união e da ação social, que dedicam suas energias para a melhoria das condições de vida da comunidade, mostrando que 


\section{Atos de Pesquisa em Educação - ISSN 1809-0354 \\ Blumenau, v. 13, n.2, p.271-295, mai./ago. 2018 \\ DOI: http://dx.doi.org/10.7867/1809-0354.2018v13n2p271-295}

a cooperação solidária na busca de soluções de alguns dos problemas essenciais da cidade (como o lixo, a saúde, o trabalho, a alimentação, a prevenção ao uso de drogas e a autoestima) contribuem para uma melhor construção social, para uma melhor organização do espaço e para a formação cidadã.

No que diz respeito às celebrações, podem ser mencionadas tanto aquelas predominantes de uma determinada cultura, no caso a portuguesa (como a procissão, pelo mar, da Nossa Senhora dos Navegantes e a Festa do Divino Espírito Santo, da Igreja Católica), quanto aquelas das diferentes culturas que compõem o município. Só no ano de 2015, a Quermesse de Garopaba reuniu mais de 20.000 pessoas para assistirem música, dança e teatro, como o Boi de Mamão, contos de fadas, danças açorianas, hip-hop, jazz, dança do ventre e cantos gaúchos, sertanejos, gospel e rock, desfiles de carros de boi, entre outras atrações, além da gastronomia diversa. Também, na cidade, são realizados eventos que celebram o sincretismo entre rituais pagãos ancestrais e a religião cristã, como o carnaval de verão e as múltiplas festas juninas que se estendem pelas escolas e grupos comunitários do município durante $o$ inverno. Artistas locais, nacionais e internacionais encontram espaço para divulgação e comércio de suas obras tanto nestes eventos quanto em feiras e espaços públicos. Existem grupos de dança bastante atuantes e reconhecidos nacionalmente, como a Cia Atitude, assim como a possibilidade de apreciar e comprar pinturas de paisagens locais e miniaturas de barco e engenhos de madeira, ao lado de quadros de arte moderna. Destacam-se no município artistas como o Fabrício Rodrigues Garcia, o Manohead, que oferece oficinas de pintura à comunidade, e Abdel Oliveira, com sua técnica em estilo barroco. Também poetas, como o pescador Maurício dos Passos, o Moriço. Letristas, escritores, desenhistas, cantores gospel, bandas de rock, reggae e sertanejo emergem atualmente no cenário intercultural da cidade. Inclusive, no período do verão, grupos indígenas M'byá Guarani e Kaigang imigram para venderem seus produtos artesanais de cestarias, acessórios, animais de madeira da fauna catarinense, arcos e flechas, e divulgarem suas culturas por meio do canto.

Os diferentes atores sociais influenciam e são influenciados neste meio ambiente de riqueza intercultural única. Em Garopaba, turistas alemães compram e vestem acessórios Kaigang enquanto comem pratos típicos como o pirão com peixe e bebem a cachaça dos engenhos. Guaranis tomam o sorvete artesanal local e 


\section{Atos de Pesquisa em Educação - ISSN 1809-0354 \\ Blumenau, v. 13, n.2, p.271-295, mai./ago. 2018 \\ DOI: http://dx.doi.org/10.7867/1809-0354.2018v13n2p271-295}

comunicam-se através de celulares japoneses. Moradores locais e turistas de diversas localidades do Brasil e do mundo envolvem-se em diferentes esportes, tanto tradicionais, como o futebol e o tênis, mas também os de aventura, como surfing, trecking, escalada, parapente, mountain bike e motocross, influenciados pela geografia e paisagem que favorecem a prática. A oferta de cursos de artes marciais locais, como capoeira, e também trazidos de outros lugares, como o jiu-jitsu, o judô e o muai-thay, também ocorreu na última década. Mesmo existindo postos de saúde pública e duas policlínicas privadas com médicos e enfermeiros que fazem tratamento alopático, alguns moradores ainda procuram as benzedeiras, como Dona Lita, que sincretizaram aspectos cristãos, indígenas e africanos em suas rezas de cura e receitas de chás e remédios de plantas medicinais. Além dos templos evangélicos e católicos, também há palestras e atendimentos fraternos em uma casa espírita próxima ao centro da cidade, como também atividades na umbanda. $E$, complementando a riqueza espiritual do município, têm-se ampliado na região espaços de práticas e terapias alternativas orientais, como o budismo, yoga e Ayurveda.

O estudo apresentado neste texto mostrou que Garopaba é sinergicamente construída pela riqueza e o sincretismo de diferentes culturas em suas relações com o meio ambiente ao longo do tempo. Multicultura em uma diversidade ambiental que forma uma comunidade única e criativa que busca, em meio aos conflitos que se desdobram em seus espaços, a construção coletiva em sua organização e modos de vida; que, ao mesmo tempo em que explora e modifica o ambiente para o seu desenvolvimento, também é modificado e determinado por ele. E por isso é essencial que se considere a intercultura e as características ambientais próprias de Garopaba na elaboração do currículo e nas ações educativas locais, dada a importância das inter-relações das diferentes culturas na construção histórica e coletiva dos espaços e na formação da paisagem. Neste sentido, a rede municipal já apresentou alguns avanços, com a inclusão dos povos originais e dos africanos na produção de um livro didático complementar sobre a história e a geografia de Garopaba. Foi uma importante iniciativa construir um instrumento educativo próprio, que não deve restringir-se a uma ou outra disciplina, mas que sirva de fonte de conhecimento particular que dialogue com as fontes de conhecimento científico geral tradicionalmente usado nas escolas. 
$\mathrm{E}$ isso deve ser incentivado, aprofundado, continuamente melhorado; dialogar com a ciência acadêmica e os saberes da comunidade e sempre se reavaliar na busca do real entendimento e da coerência entre o discurso e a realidade, no sentido de trazer instrumentos para a reflexão e a possível superação desta realidade, nos casos de conflitos.

\section{ALGUNS CAMINHOS POSSÍVEIS}

Sem a intenção de esgotar as possibilidades para a superação do modelo tradicional de currículo - enquanto rígido, homogeneizador e vertical - considera-se neste estudo algumas possibilidades de instrumentos pedagógicos e ações refletidas que podem construir caminhos mais próximos da abordagem intercultural e da sustentabilidade socioambiental:

- A formação continuada dos professores numa abordagem crítica pode ser um princípio de todo projeto educativo que almeja a integração das pessoas em processos democráticos de educação. Professores que aprendem por meio da reprodução de conteúdos transmitidos unilateralmente tendem a reproduzilos aos seus alunos. A formação crítica dos docentes favorece a propagação da prática reflexiva aos estudantes.

- $\quad$ A integração de aspectos interculturais e do meio ambiente locais aos temas e conteúdos do plano de ensino abrem espaço para a ação pedagógica organizada neste sentido, possibilitando a produção de materiais próprios (como fez o município de Garopaba) que podem servir como ponto de partida para uma investigação mais crítica e profunda sobre diferentes assuntos relacionados. O conhecimento da realidade local permite abordar os diferentes temas de modo contextualizado e próximo à vida cotidiana da comunidade e, ao mesmo tempo, pode despertar a curiosidade científica pelo conhecimento, estudando os conteúdos teóricos a nível global e relacionando-os e/ou aplicando-os em uma realidade próxima.

- Ensinar o método científico e instigar à investigação de temas diversos dentro da realidade local é uma possibilidade bastante prolífica e capaz de abarcar descobertas interessantes e úteis. Permite registrar paisagens, situações e memórias de antigas histórias; a importância de personalidades e 
grupos locais atuantes; a possibilidade de trazer à escola e abrir à comunidade espaço para dialogar com pessoas de conhecimentos diversos - científicos, de utilidade pública e de saberes locais - além de poder coletar materiais junto às pessoas para a criação de um acervo histórico e natural para a interação educativa com a comunidade (em feiras multidisciplinares ou, de modo permanente, em museus ou acervos interativos, por exemplo).

- Por meio da investigação de campo, é possível visitar com os estudantes os lugares históricos e a geografia local, visitar e entrevistar pessoas atuantes nos órgãos públicos e na comunidade, buscando conhecer as diferentes realidades, os aspectos do passado, do presente e as projeções para o futuro, dialogando com a comunidade e dando espaço para que as pessoas expressem o seu ponto de vista.

- Experiências sensoriais com a realidade local (o meio ambiente, plantas e animais, a gastronomia, a arte, a música, a dança, os espaços, as construções, entre outras tantas formas) oferecem uma imersão sensitiva no contexto intercultural e socioambiental, exercitando o movimento, experimentando sabores, texturas, cores, relacionando memórias, imprimindo emoções e favorecendo a aprendizagem concreta das experiências.

- Ainda, é importante salientar sobre o estudo dos conflitos socioambientais de maneira contextualizada, de modo a favorecer o entendimento da origem destes conflitos no intuito de buscar soluções sustentáveis aos mesmos. Os alunos, com orientação dos professores, podem pesquisar e/ou investigar sobre as relações entre as pessoas e delas com o ambiente e expressar suas impressões e ideias de modo diversificado, pela música, pelo texto, poesia, pintura, teatro, dança, por meio de uma síntese crítica, painel, simpósio, ou um diálogo crítico em aula, um diálogo crítico com a comunidade e, até mesmo, buscar ideias viáveis e sustentáveis para a superação destes conflitos. Redigindo textos e registrando imagens de modo organizado, é possível oferecer aos gestores do poder público algumas ideias sobre o diagnóstico de diferentes espaços da comunidade e algumas sugestões de melhoria, como forma de contribuir de modo cidadão para a superação dos mesmos. 
Ao conhecer a comunidade e dialogar com as diferentes formas culturais, é possível construir uma identidade intercultural nas escolas, enriquecendo o currículo com uma abordagem mais crítica e atuante, fazendo um diálogo entre o conhecimento científico, as características socioambientais e os saberes locais.

\section{ALGUMAS CONSIDERAÇÕES}

Sem a intenção de esgotar os elementos para esta discussão, os resultados do estudo levam a inferir sobre a necessidade de revisão do currículo padronizado e universalizado nas escolas, no sentido de construir conhecimentos científicos de relevância global e que contemple os saberes da comunidade, a complexidade e as particularidades sociais e ambientais da região, haja vista que as pessoas constroem suas vidas e seus espaços enquanto seres biológicos e sociais, ecológicos e interculturais, integrantes e inter-relacionados com o ambiente em que vivem. E, para que isso se concretize, um dos grandes desafios na educação é buscar a superação da abordagem tradicional que segrega e que, portanto, favorece e reproduz a cultura de degradação da sociedade e do meio ambiente. Com base neste estudo, é possível inferir que não existe uma normalidade homogênea de pessoas, culturas, lugares e relações. O processo educativo consciente deve considerar um ambiente diverso, complexo e integrado de relações socioambientais que estão sempre em mudança e movimento. Também, que contemple as diferentes possibilidades pedagógicas de modo a oferecer às diferentes pessoas o direito de construir e produzir conhecimento com organizada liberdade de escolha e atuação, de acordo com seus interesses coletivos e particularidades.

A sociedade e o mundo não podem ser compreendidos em separado, uma vez que estão interligados pelas suas inter-relações ao longo da história. O estudo e reflexão a respeito da intercultura de Garopaba e suas vivências com o meio ambiente ilustram claramente o quanto os aspectos culturais humanos são constituídos e influenciados pelos aspectos ambientais, assim como também constituem e influenciam as características do ambiente. Mostram como a intercultura, em integração com a diversidade ambiental, constrói a realidade. A dinâmica social humana deve ser compreendida também como um fenômeno biológico e ecológico, portanto, é natural e construído em conjunto com as outras pessoas: 
O conhecimento do conhecimento obriga. Obriga-nos a assumir uma atitude de permanente vigília contra a tentação da certeza, a reconhecer que nossas certezas não são provas da verdade, como se o mundo que cada um vê fosse o mundo e não um mundo que construímos juntamente com os outros (MATURANA; VARELA, 2007, p. 267).

Sem amor, sem a aceitação da existência do outro, não há socialização e sem socialização não há humanidade. A humanidade faz-se na relação de unicidade. É preciso, como afirma Morin (2004), substituir o pensamento que isola, separa e reduz pelo pensamento que une, que considera o complexo como estrutura. As múltiplas culturas são manifestações da diversidade humana que, coexistindo e interrelacionando-se, formam a estrutura social que se faz no e com o meio ambiente. Pois, de acordo com Moraes (2007, p. 21), a complexidade - que é inerente à realidade:

Como fator constitutivo da vida, significa que ela rege os acontecimentos, as ações, os eventos e os processos e, desta forma, ontológica e epistemologicamente falando, ela não permite separar ser/realidade, sujeito/objeto, educador e educando, objetividade/subjetividade, sujeito, cultura e sociedade, [...] É ela que nos informa que a realidade educacional não é previsível, ordenada e determinada, não podendo ser aprisionada por este ou aquele modelo de ciência, nem por este ou aquele pensamento reducionista, único e verdadeiro. (MORAES, 2007, p.21).

Portanto, reduzir a abordagem educacional a um modelo culturalmente imposto restringe o entendimento da realidade socioambiental que é complexa e integrada. Ensinar e aprender são processos que, na busca de um entendimento mais holístico do mundo, precisam considerar a complexidade das múltiplas culturas que construíram e ainda constroem seus espaços em sinergia com os diversos ambientes nos quais e com os quais interagem. Ainda, segundo Moraes (2007, p. 22), pode-se aprimorar a atuação docente por meio de um melhor entendimento acerca dos fenômenos complexos, de modo a ampliar o campo de construção teórica:

[...] esta mesma causalidade complexa nos permite ver de outra maneira os fenômenos complexos, cuja dinâmica é processual, inacabada e transitória, bem como as interações sujeito/objeto, teoria/prática. Nestas, a circularidade existente entre ambas rompe com a causalidade linear, pois a ação de uma retroage sobre a outra, realimentando-a e modificando-a. Uma poliniza a outra. Uma está sempre fertilizando ou fertilizada pela outra. Assim, melhorando a nossa prática, esta melhoria retroagirá informacionalmente sobre os conceitos trabalhados e iluminará a construção teórica desenvolvida. (MORAES, 2007, p.22).

A transformação do mundo é possível quando o sujeito tem consciência das conexões, da causalidade histórica, das inter-relações das partes no e com o todo. É 
necessário um método de conhecimento do mundo que busque o entendimento da origem histórico-cultural e dos processos dos fenômenos, não se restringindo unicamente a uma imposição universal ou às causas e efeitos imediatos do pragmatismo. Pois "[...] conhecer o humano não é separá-lo do Universo, mas situálo nele" (MORIN, 2003, p. 37).

Neste contexto, é possível criar espaços e condições, dentro e fora das escolas, para que professores e alunos possam produzir e construir conhecimentos de forma integrada, relacionando os diferentes aspectos da realidade no e com o todo, transcendendo as fronteiras da pedagogia tradicional, em que a sustentabilidade não se restringe apenas às relações das pessoas com a Natureza, mas também aos indivíduos entre si. Um caminho que amplia o campo de conhecimento, que aborda e relaciona os conteúdos de forma interdisciplinar e transversal, que considere os diferentes aspectos da realidade. E um possível caminho para este campo de conhecimento é a educação numa abordagem intercultural. O foco, nesta concepção, é a valorização dos sujeitos, que são os que criam e sustentam as culturas, refere-se à interação entre os sujeitos no processo de reconhecer seus direitos e dignidade. Vale ressaltar que interagir com diferentes culturas contribui para a compreensão de lógicas ou pontos de vistas diferentes de interpretar a realidade ou a relação social. Educar numa perspectiva intercultural implica mudanças na estrutura da prática educativa para poder garantir oportunidades para todas as pessoas de modo a abarcar a complexidade das relações humanas entre indivíduos e culturas diferentes.

É compreender que culturas distintas podem relacionar-se de modo a não anularem suas diferenças, mas permitir e favorecer o desenvolvimento das potencialidades de cada uma. Esta abordagem educativa propicia a construção de um projeto comum em que as diferenças são integradas. Os conflitos, na concepção de Coppete, Fleuri e Stoltz (2012, p. 252): "são entendidos como mobilizadores do processo de aprendizagem". A educação na perspectiva intercultural orienta-se na construção de uma sociedade plural e protagonista.

Considera-se neste estudo algumas ações pedagógicas que podem contribuir para a construção crítica e protagonista de um currículo mais próximo à realidade da comunidade. Um projeto que contempla, além dos conteúdos teóricos científicos, também, a interculturalidade, as características socioambientais e os saberes locais. 
Sugere-se: a formação crítica dos professores de modo continuado, favorecendo a propagação do olhar crítico aos alunos; a inclusão de temas curriculares relacionados à realidade local da comunidade, com a possibilidade de produzir materiais próprios (como o exemplo de Garopaba) e usá-los como ponto de partida para o aprofundamento de diversos assuntos relacionados; a investigação de questões locais por meio do método científico, buscando conhecer a realidade próxima e relacionar/aprofundar por meio dos estudos teóricos e experimentais, com a possibilidade de criar um acervo temporário (em feiras e amostras) ou permanente (como um museu local); atividades de campo que levem professores e estudantes para os diferentes espaços da comunidade, onde poderão dialogar com as pessoas sobre suas realidades em seu próprio contexto de vida, além de vivenciar as diferentes paisagens locais; oferecer experiências sensoriais com os aspectos ambientais e interculturais, estimulando sentidos e imprimindo memórias relacionadas às vivências; e o estudo crítico dos conflitos socioambientais, abrindo muitas possibilidades de abordagens, expressões artísticas e intelectuais, como também de criar oportunidades para o diálogo com os órgãos públicos, por meio da realização e apresentação de estudos diagnósticos e sugestões de melhorias aos problemas levantados.

E é neste movimento que se propõe, com base nas ideias de Fleuri (2003), Walsh (2009) e Coppete, Fleuri e Stoltz (2012), uma pedagogia mais crítica e atuante em relação às questões socioambientais no sentido da intercultura. Uma práxis educativa, de ação, reflexão, criação e recriação das diferentes formas de existir e se relacionar; que contemple as diferentes culturas de modo integrado, considerando suas singularidades, apropriando-se de novas formas, transformando algumas e superando outras que não tenham mais sentido na mudança histórica e espacial do tempo. Uma educação que questione os problemas no intuito de transcendê-los por meio do diálogo, da ação crítica individual e coletiva. Uma educação que respeite as peculiaridades biorregionais, históricas e culturais que construíram e constroem os espaços e as relações socioambientais que constituem a realidade que se conhece.

\section{CRISTINA OLIVEIRA MACHADO FARACO}


Mestre em Educação pela UNISUL. Especialista em Gestão Ambiental pelo ISEPG/ACE. Graduada em Biologia pela UNISINOS. Professora titular de Biologia e Ciências na Escola de Educação Básica Prefeito Luiz Carlos Luiz, Garopaba (SC).

\section{VERA LÚCIA CHACON VALENÇA}

Doutora em Psychlogie Appliqueé - Université Rèné Descartes, Sorbonne - Paris. Professora do Programa de Pós-Graduação em Educação da UNISULI.

\section{REFERÊNCIAS BIBLIOGRÁFICAS}

BAUMAN, Z. Ensaio Sobre o Conceito de Cultura. Rio de Janeiro: Zahar, 2012. 228 p.

BESEN, J. A. 1980 São Joaquim de Garopaba: recordações da freguesia. Passo Fundo: Pe. Berthier, 1996. 197p.

BRASIL. Diretrizes Curriculares Nacionais para a Educação Básica. Brasília: MEC, SEB, DICEI, 2013, 562 p.

. Decreto de 14 de setembro de 2000. Diário Oficial da União - Seção 1 15.9.2000. Disponível em:

<http://www2.camara.leg.br/legin/fed/decret_sn/2000/decreto-91-14-setembro-2000373393-publicacaooriginal-1-pe.html>. Acesso em: 21 jun. 2015.

. Parâmetros Curriculares Nacionais. Brasília: MEC/SEF, 1997. 122 p.

CAPRA, F. As Conexões Ocultas: ciência para uma vida sustentável. São Paulo:

Pensamento-Cultrix, 2003. 296 p.

COPPETE, M. C.; FLEURI, R. M.; STOLTZ, T. A Educação para a Diversidade numa Perspectiva Intercultural. Revista Pedagógica UNOCHAPECÓ. Chapecó, Ano 15, vol. 01, n. 28, p. 231-262. Jan./Jun. 2012.

DEBLASIS, P. et al. Sambaquis e Paisagem: dinâmica natural e arqueologia regional no litoral sul do Brasil. Arqueologia Sul-Americana. vol.3, n. 1, p. 29-61, jan. 2007.

FARIAS, D. S. E. et al. Arqueologia na Mata Atlântica: pesquisando os sítios arqueológicos da encosta catarinense, municípios de Rio Fortuna e Braço do Norte: linha de transmissão 69 kV PCH Barra do Rio Chapéu, subestação Braço do Norte. S.I.: s.n. 2011. 12 p. (cartilha impressa)

FARIAS, D. S. E.; DEMATHÉ, A.; SILVA, K. K. Garopaba: Memória e Preservação. Florianópolis: Governo do Estado de Santa Catarina/CASAN, 2014. (folder impresso) 
FLEURI, R. M. Intercultura e Educação. Revista Brasileira de Educação. Campinas: UNICAMP, p. 16-35, maio/jun./jul./ago. 2003. Disponível em: <www.scielo.be/pdf/rbedu/n23/n23a02>. Acesso em: 19 abr. 2015.

GAROPABA. Prefeitura Municipal. História, Geografia e Meio Ambiente de Garopaba. [S.d.]. Disponível em: <www.garopaba.sc.gov.br>. Acesso em: 07 set. 2004.

GONÇALVES, C. W. P. Os (Des)caminhos do Meio Ambiente. São Paulo: Contexto, 1989. $146 \mathrm{p}$.

IBGE. Instituto Brasileiro de Geografia e Estatística - Santa Catarina: Garopaba: dados geográficos e estatísticos. [S.d]. Disponível em:

<http://www.ibge.com.br/cidadesat/xtras/perfil.php?lang=\&codmun=420570\&search= santa-catarina\%7Cgaropaba>. Acesso em: 21 jun. 2015.

JECUPÉ, K. W. A Terra dos Mil Povos: História indígena do Brasil contada por um índio. São Paulo: Petrópolis, 1998. 115 p.

MATURANA, H.; VARELA, F. A Árvore do Conhecimento: as bases biológicas da compreensão humana. 6. ed. São Paulo: Palas Athena, 2007. 283 p.

MCLAREN, P. Fúria e Esperança: a pedagogia revolucionária de Peter McLaren entrevista com Peter McLaren. Currículo Sem Fronteiras: revista para uma educação crítica e emancipatória. v. 1, n. 2, p. 171-188, jul./dez. 2001. Disponível em:

$<w w w$.curriculosemfronteiras.org/vol1iss2articles/mclaren.pdf>. Acesso em: 19 abr. 2015.

MORAES, M. C. A Formação do Educador a Partir da Complexidade e da Transdisciplinaridade. Diálogo Educacional, Curitiba, v. 7, n.22, p. 13-38, set./dez. 2007. Disponível em:

<http://www2.pucpr.br/reol/pb/index.php/dialogo?dd1=1571\&dd99=view\&dd98=pb>. Acesso em: 20 out. 2015.

MORIN, E. Os Sete Saberes Necessários à Educação do Futuro. 8. ed. Brasília: UNESCO, 2003. $116 \mathrm{p}$.

A Cabeça Bem-Feita: repensar a reforma, reformar o pensamento. 9. ed. Rio de Janeiro: Bertrand Brasil, 2004. 128 p.

SAVIANI, D. Escola e Democracia: teorias da educação, curvatura da vara, onze teses sobre educação e política. 32 ed. Campinas: Autores Associados, 1999. 99p.

SILVA, T. T. Documentos de Identidade: uma introdução às teorias do currículo. 3. ed. Belo Horizonte: Autêntica, 2010. 156 p.

VALENTIM, M. História de Garopaba: da armação baleeira à comarca. Garopaba: Prefeitura Municipal de Garopaba, 2007. 208 p. 
Atos de Pesquisa em Educação - ISSN 1809-0354

Blumenau, v. 13, n.2, p.271-295, mai./ago. 2018

DOI: http://dx.doi.org/10.7867/1809-0354.2018v13n2p271-295

WALSH, C. Interculturalidade Crítica e Pedagogia Decolonial: in-surgir, re-existir, e re-viver. In: CANDAU, V. M. (Org.). Educação Intercultural na América Latina: entre concepções, tensões e propostas. Rio de Janeiro: GECEC, 2009. p. 12-42. 